\title{
Effect of metformin on apoptosis, cell cycle arrest migration and invasion of A498 cells
}

\author{
ZHIQING FANG ${ }^{1,2}$, XIULIAN XU ${ }^{3}$, ZUNLIN ZHOU $^{1}$, ZHONGHUA XU $^{1}$ and ZHAOXU LIU ${ }^{1,4}$ \\ ${ }^{1}$ Department of Urology, Qilu Hospital of Shandong University; ${ }^{2}$ The Key Laboratory of Cardiovascular Remodeling and \\ Function Research, Chinese Ministry of Education and Chinese Ministry of Public Health; \\ ${ }^{3}$ Surgery Department, Qilu Hospital of Shandong University; ${ }^{4}$ School of Nursing, \\ Shandong University, Jinan, Shandong 250012, P.R. China
}

Received September 28, 2013; Accepted March 5, 2014

DOI: $10.3892 / \mathrm{mmr} .2014 .2097$

\begin{abstract}
Previous studies have demonstrated that metformin (Met) may reduce the risk of cancer development. In the present study, the anti-cancer effects of Met in A498 cells were investigated. It was found that Met inhibited A498 cell proliferation in a time- and dose-dependent manner, as well as induced the activation of AMP-activated protein kinase. It was also demonstrated that Met promoted A498 cell apoptosis and mechanistic studies suggested that this was mediated by the downregulation of B-cell lymphoma 2 and concurrent upregulation of $\mathrm{Bcl}-2$-associated $\mathrm{X}$ protein. In addition, it was observed that Met induced G1 cell cycle arrest by decreasing cyclin D1 expression. Furthermore, the results demonstrated that Met reduced A498 cell migration and invasion in vitro by decreasing matrix metalloproteinase-2, which indicated its potential to inhibit renal cancer metastasis. In combination, these results provide evidence that Met is important in anti-renal cancer therapy, and thus may serve as a novel and efficient agent for renal cancer treatment.
\end{abstract}

\section{Introduction}

Renal cell carcinoma (RCC) accounts for $\sim 90-95 \%$ of all kidney neoplasms $(1,2)$ and surgery remains the only definitive treatment for RCC (3). Approximately one third of patients with RCC present with metastases at diagnosis and $40 \%$ of patients develop metastases following nephrectomy (4). RCC is highly refractory to conventional therapeutic strategies, including radiotherapy, chemotherapy and hormonal therapy $(5,6)$. There are a number of options for the treatment of metastatic RCC (mRCC), including molecular targeting drugs and immunotherapy (7), however, novel therapeutic targets are urgently required for controlling the development of mRCC.

Correspondence to: Professor Zhaoxu Liu, Department of Urology, Qilu Hospital of Shandong University, 107 Wenhua Xi Road, Jinan, Shandong 250012, P.R. China

E-mail: zhaoxvl@sdu.edu.cn

Key words: metformin, apoptosis, migration, invasion, renal cancer
Metformin (Met) is a widely prescribed anti-diabetic agent and is used as first-line therapy for patients with type 2 diabetes mellitus (8). In addition to its anti-diabetic effect, Met has previously been demonstrated to exhibit anti-cancer effects. Observational studies have revealed that diabetics who take Met have a lower risk of cancer incidence $(9,10)$. A number of studies have also demonstrated that Met inhibits cancer cell proliferation, migration and invasion by activating AMP-activated protein kinase (AMPK) $(11,12)$. These studies indicate that Met may be important in cancer protection.

In the present study, the anti-proliferative and anti-metastatic effects of Met on A498 cells were investigated in vitro, as well as the molecular mechanisms underlying the anti-cancer effects of Met in order to determine the potential of Met as a novel chemotherapeutic drug.

\section{Materials and methods}

Cell culture and reagents. Human A498 cells were obtained from the American Type Culture Collection (Manassas, VA, USA) and cultured in high glucose Dulbecco's modified Eagle's medium (DMEM; HyClone Laboratories, South Logan, UT, USA) with $10 \%$ fetal bovine serum (FBS) in $5 \%$ $\mathrm{CO}_{2}$ at $37^{\circ} \mathrm{C}$. Met (1,1-dimethylbiguanide hydrochloride) was purchased from Sigma-Aldrich (St. Louis, MO, USA).

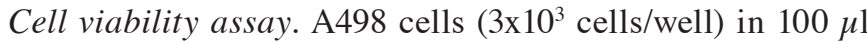
medium were seeded in 96-well plates. Following $12 \mathrm{~h}$, the medium in each well was replaced with medium containing different concentrations of Met (16 and $32 \mathrm{mM})$ and incubated for $24 \mathrm{~h}$. Cell viability was then determined using the MTT assay as previously described (13). The absorbance values were determined using a microplate reader (Bio-Rad, Hercules, CA, USA).

Effect of Met on cell morphology. When A498 cells reached $60 \%$ confluence, the cells were washed with phosphate-buffered saline and then exposed to $16 \mathrm{mM} \mathrm{Met}$ for $48 \mathrm{~h}$. The morphology of treated A498 cells was observed under a microscope (Olympus, Tokyo, Japan) and photomicrographs were captured with an Olympus digital camera (Olympus). 
In vitro scratch assay. A498 cells were seeded in 24-well plates. Following incubation with Met $(16 \mathrm{mM})$ for $24 \mathrm{~h}$, each well was scratched using a $200 \mu \mathrm{l}$ pipette tip, and further incubated at $37^{\circ} \mathrm{C}$ with Met $(16 \mathrm{mM})$. Images of the scratch area were then captured following $24 \mathrm{~h}$ and the distance between the two cell edges was analyzed using ImageJ software (National Institutes of Health, Bethesda, MA, USA).

In vitro invasion assay. The transwell system ( 24 wells, $8 \mu \mathrm{m}$ pore size with polycarbonate membrane; Corning Costar, Lowell, MA, USA) coated with $2 \mathrm{mg} / \mathrm{ml}$ basement membrane Matrigel (BD Biosciences, Franklin Lakes, NJ, USA) was used for the in vitro invasion assays. Briefly, A498 cells were pretreated with Met $(0,16$ and $32 \mathrm{mM})$ for $24 \mathrm{~h}$ and then seeded (at a density of $5 \times 10^{5}$ ) into the upper chamber using serum free medium. DMEM, containing 20\% FBS and Met (0, 16 and $32 \mathrm{mM}$ ), was then added to the lower chamber. Following $24 \mathrm{~h}$ of incubation, the cells attached to the lower surface were fixed with methanol and stained with $0.1 \%$ crystal violet. Five fields of vision were randomly selected for each chamber and the number of cells was counted under a light microscope (Olympus) and analyzed statistically.

In vitro migration assay. For the migration assay, the cells were seeded in upper chambers without Matrigel. The rest of the assay was performed as the invasion assay. The number of cells on the lower surface was counted in five randomly selected fields and the cell number was then analyzed statistically.

Flow cytometric analysis of the cell cycle and apoptosis. Briefly, $1 \times 10^{5}$ cells/well were cultured in 6-well plates and incubated overnight. The cells were then treated with 0,16 and $32 \mathrm{mM}$ Met for $48 \mathrm{~h}$. Following treatment, the cells were harvested and resuspended in $100 \mu \mathrm{l}$ binding buffer. The cells were then incubated with RNase for $30 \mathrm{~min}$ at $37^{\circ} \mathrm{C}$ and $5 \mu \mathrm{l}$ propidium iodide (PI) was added, followed by a $10 \mathrm{~min}$ incubation in the dark. The samples were subsequently analyzed using flow cytometry and the percentage of cells in each phase was determined using WinMDI V2.9 software (The Scripps Research Institute, San Diego, CA, USA).

Western blot analysis. Preparation of whole cell protein extracts and western blot analysis were conducted as previously described (14). Antibodies against human p-AMPK, AMPK, B-cell lymphoma 2 (Bcl-2), Bcl-2-associated X protein (Bax), poly ADP ribose polymerase (PARP), cyclin D1, matrix metalloproteinase-2 (MMP-2), GAPDH and secondary antibodies were purchased from ImmunoWay Biotechnology (Newark, DE, USA).

Statistical analysis. Student's two-tailed t-test was used to determine statistical differences between the treatment and control cells. $\mathrm{P}<0.05$ was considered to indicate a statistically significant difference. All data are presented as the mean \pm standard deviation of three independent experiments.

\section{Results}

Met inhibits the proliferation of A498 cells. The effect of Met on A498 cell proliferation was determined using the
MTT assay. It was revealed that Met significantly inhibited the proliferation of A498 cells in a time- and dose-dependent manner $\left({ }^{* *} \mathrm{P}<0.01\right.$; Fig. 1A). To investigate the pro-apoptotic and anti-metastatic effect of Met on A498 cells, Met concentrations of 16 and $32 \mathrm{mM}$ were used in subsequent experiments.

Effect of Met on the cell morphology of renal cancer cells. The alterations in the morphology of A498 cells following treatment with Met $(16 \mathrm{mM})$ for $48 \mathrm{~h}$ are shown in Fig. 1B. Met caused A498 cells to lose plasma membrane integrity and the majority of the cells became lean and thin.

G0/G1 cell cycle arrest in A498 cells by Met. To investigate the effects of Met on cell cycle distribution, A498 cells were treated with 16 and $32 \mathrm{mM}$ Met for $48 \mathrm{~h}$ and the cells were then analyzed using flow cytometry. As shown in Fig. 2, Met increased the number of cells in the G0/G1 phase and decreased the number of cells in the $\mathrm{S}$ phase compared with the control cells $\left({ }^{* *} \mathrm{P}<0.01\right)$. Furthermore, the number of cells in the G0/G1 phase increased markedly when treated with $16 \mathrm{mM}$ Met and increased further when treated with $32 \mathrm{mM}$ Met. These results indicate that Met induced G0/G1 cell cycle arrest in A498 cells in a dose-dependent manner.

Met induces apoptosis of A498 cells. To detect and quantify the extent of apoptosis induced by Met, PI staining was used to analyze the percentage of apoptotic cells. As shown in Fig. 3, the total percentage of apoptotic cells increased from $2.64 \%$ in non-Met treated A498 cells to 8.70 and $15.20 \%$ in Met-treated cells (16 and $32 \mathrm{mM}$, respectively) following $48 \mathrm{~h}$ $\left({ }^{* *} \mathrm{P}<0.01\right)$. These results indicate that Met induced apoptosis of A498 cells in a dose-dependent manner.

Met inhibits the migration and invasion of renal cancer cells. The scratch assay was performed to investigate the effect of Met on the migration of A498 cells. As shown in Fig. 4A and B, the migration of A498 cells was reduced by Met $(16 \mathrm{mM})$.

To further investigate the effect of Met on cell migration and invasion, a transwell assay was performed on A498 cells treated with Met (16 and $32 \mathrm{mM}$ ). The results demonstrated that Met significantly inhibited the migration and invasion of A498 cells ( ${ }^{* *} \mathrm{P}<0.01$; Fig. $4 \mathrm{C}$ and $\left.\mathrm{D}\right)$.

Effect of Met on the expression of cell cycle, metastasis and apoptosis-associated proteins. To investigate the mechanisms underlying the anti-cancer effect of Met, the effect of Met on relevant cell signaling targets was investigated. Following treatment with varying concentrations of Met for $48 \mathrm{~h}$, it was demonstrated using western blot analysis that Met increased the phosphorylation of AMPK in a dose-dependent manner (Fig. 5). Correspondingly, following treatment with Met, the expression of Bcl-2, cyclin D1 and MMP-2 decreased, while the expression of Bax and cleaved PARP increased.

\section{Discussion}

Met is widely used for the treatment of diabetes mellitus (15), however, recent epidemiological and preclinical studies have demonstrated that Met is also a promising anticancer 
A

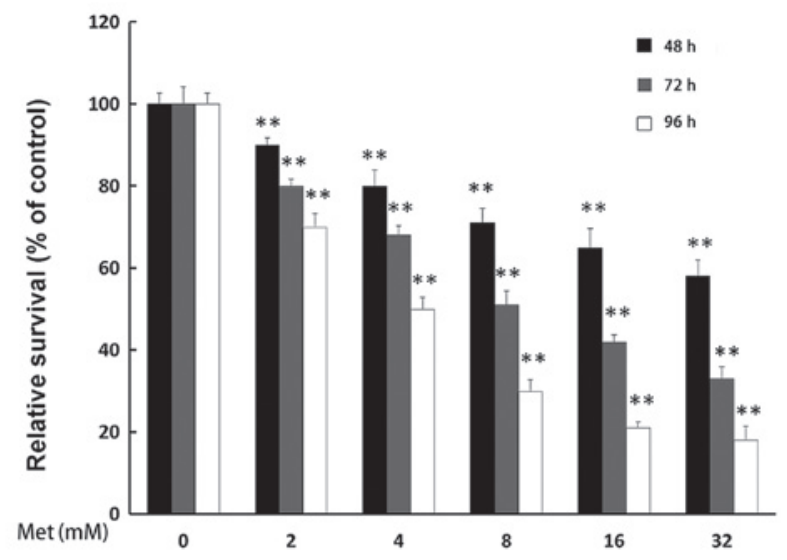

Met (mM)

B

$24 \mathrm{~h}$

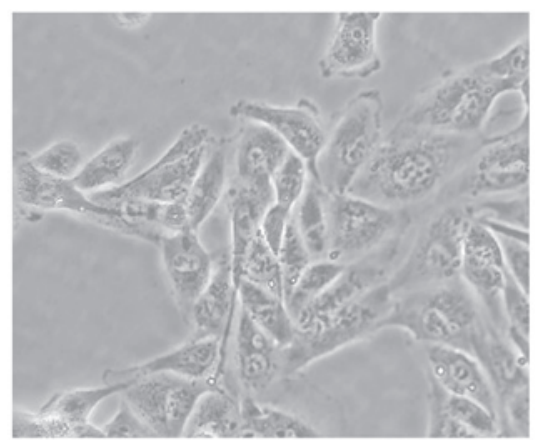

16

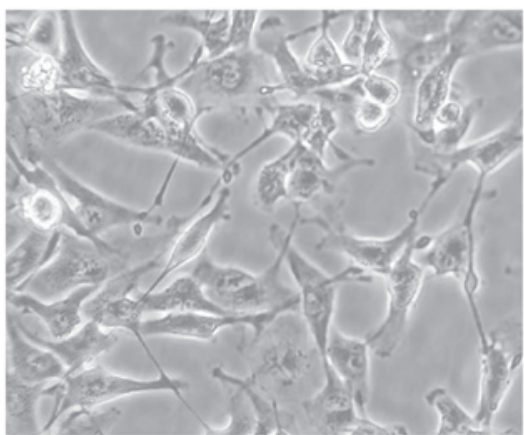

Figure 1. Met suppresses the cell viability of A498 cells. Met significantly inhibited the cell viability of A498 cells in a dose- and time-dependent manner ("P $<0.01$ ). (A) Effect of Met on cell viability was measured using the MTT assay. A498 cells were treated with Met for 48, 72 and 96 h. (B) Morphological alterations of A498 cells induced by Met (0 and $16 \mathrm{mM}$; magnification, x400). Met, metformin.

A

Met $(\mathrm{mM}) \quad 0$

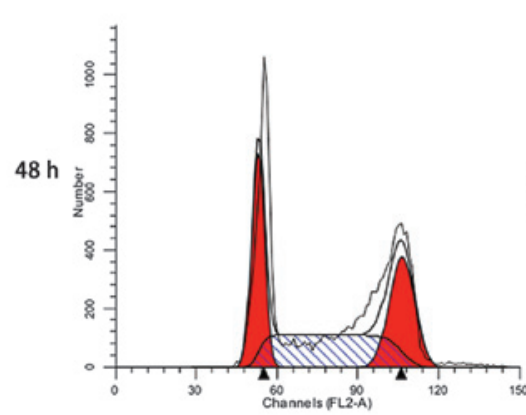

16
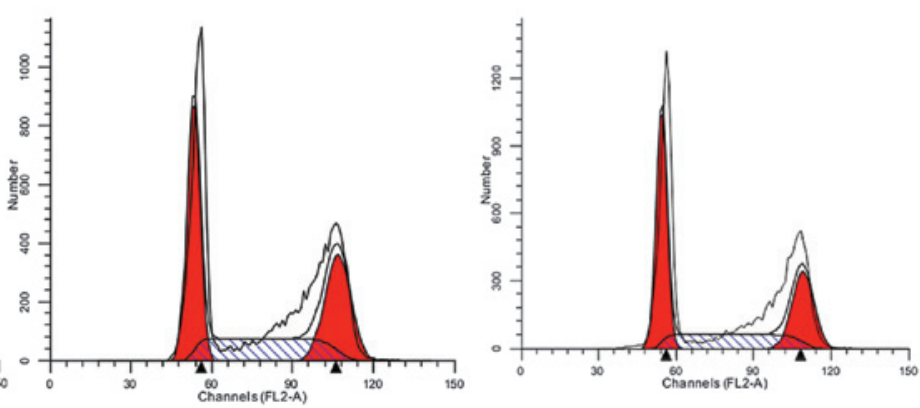

$\mathbf{B}$

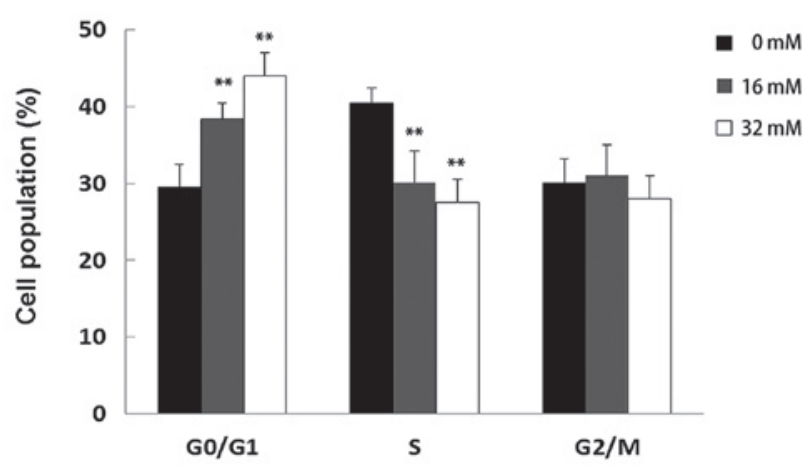

Figure 2. Met regulates the cell cycle distribution of A498 cells. (A) Flow cytometric analysis demonstrated that Met altered A498 cell cycle distribution following 48 h. (B) Met increased the number of cells in the G0/G1 phase and decreased the number of cells in the S phase compared with the control cells. Data are presented as the mean \pm standard deviation of three independent experiments. ${ }^{* *} \mathrm{P}<0.01$. Met, metformin. 
A

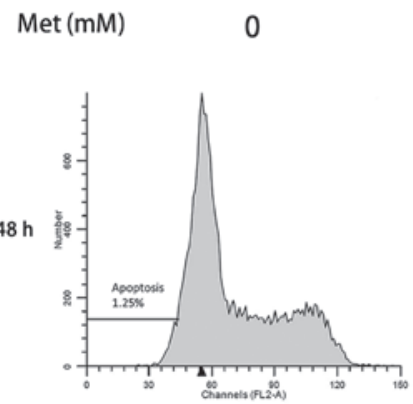

16

$\mathbf{B}$
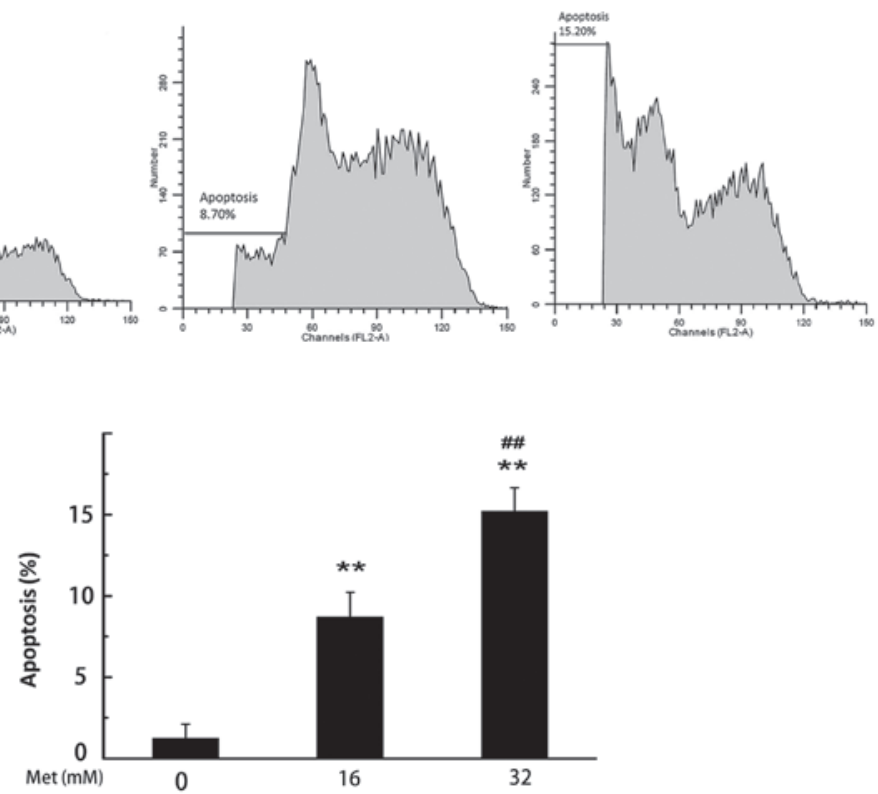

Figure 3. Met induces apoptosis of A498 cells. (A) A498 cells were treated with Met $(0,16$ and $32 \mathrm{mM})$ for $48 \mathrm{~h}$ and stained with propidium iodide. (B) Percentage of apoptotic cells. Data are presented as the mean \pm standard deviation of three independent experiments. ${ }^{* * *} \mathrm{P}<0.01$. Met, metformin.

A

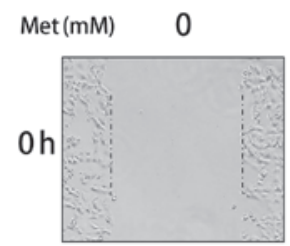

$24 \mathrm{~h}$

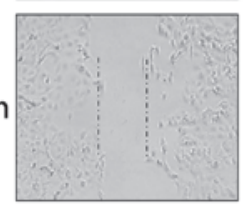

16

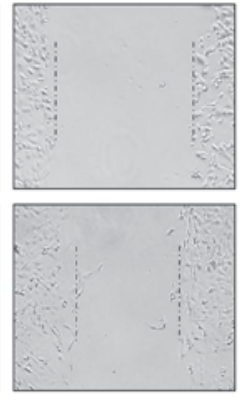

Migration

C

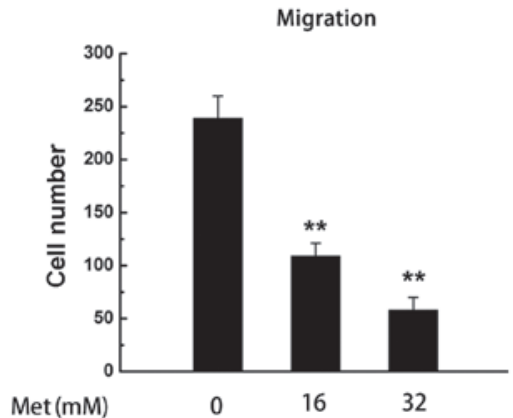

B
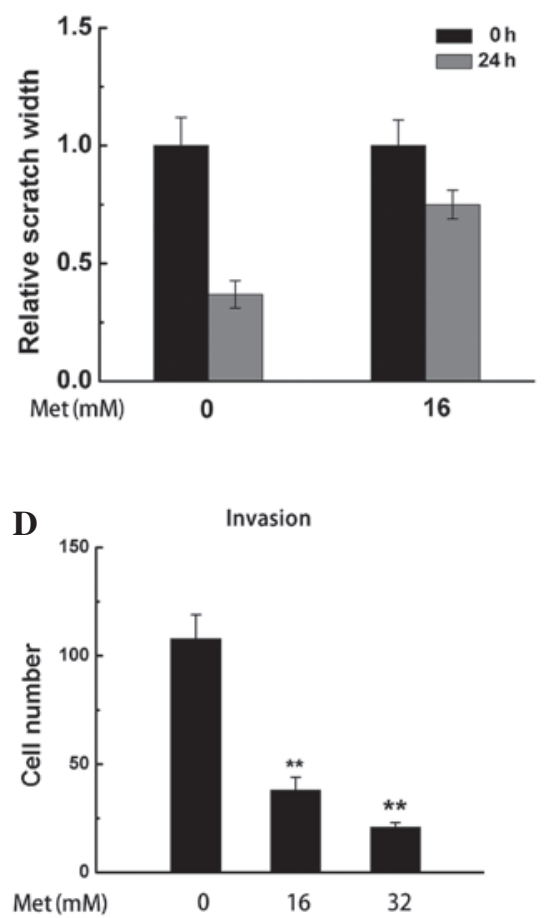

Figure 4. Cell migration and invasion ability are inhibited by Met. (A and B) Cell migration was investigated using the scratch assay. A498 cells were treated with Met $(16 \mathrm{mM})$ for $24 \mathrm{~h}$. The cells were then wounded by scratching with a pipette tip and then incubated with or without Met (16 mM) for $24 \mathrm{~h}$. (B) Met-treated A498 cells demonstrated a lower rate of wound closure compared with the control cells. (C and D) Cell migration and invasion were further investigated using the transwell assay. Following treatment with Met, the number of A498 cells that successfully (C) migrated and (D) invaded were counted. The decreased number of A498 cells indicated the inhibitory effect of Met on cell mobility. Data are presented as the mean \pm standard deviation of three independent experiments. *** $\mathrm{P}<0.01$. Met, metformin.

drug (16-18). However, the majority of studies have focused on breast and prostate cancer $(16,17,19)$ and there are few studies examining the role of Met in RCC. In order to gain insight into the possible role of Met in renal cancer, the anti-cancer effects of Met on A498 cells were investigated in the present study. 


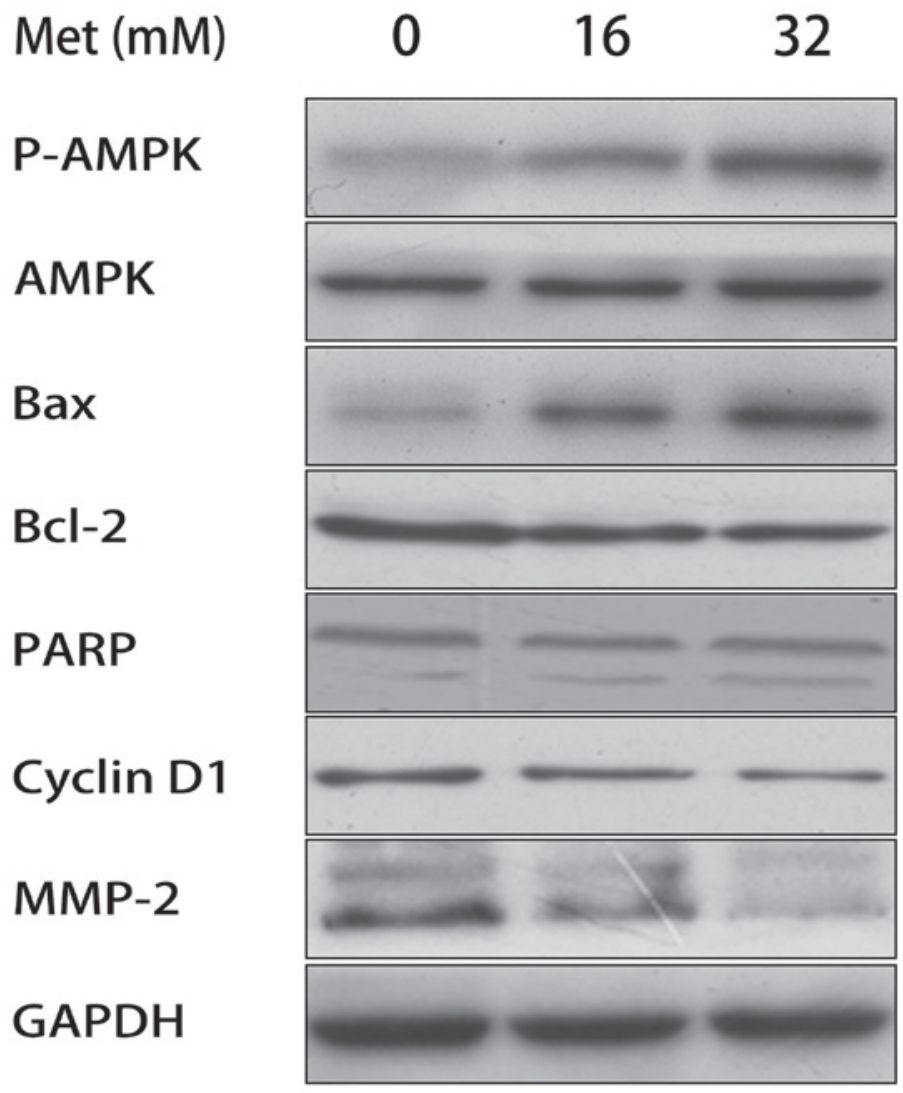

Figure 5. Effect of Met on the protein expression levels of p-AMPK, AMPK, Bcl-2, Bax, PARP, cyclin D1 and MMP-2 in A498 cells. Representative western blot showing changes in the protein levels of p-AMPK, AMPK, Bcl-2, Bax, PARP, cyclin D1 and MMP-2 in A498 cells following exposure to Met with GAPDH as a control. Met, metformin; p-AMPK, phosphorylated AMP-activated protein kinase; Bcl-2, B-cell lymphoma 2; Bax, Bcl-2-associated X protein; PARP, poly ADP ribose polymerase; MMP-2, matrix metalloproteinase-2.

AMPK is a therapeutic target for metabolic syndrome and type 2 diabetes since its activation stimulates fatty acid oxidation and enhances insulin sensitivity (20,21). AMPK directly activates mammalian target of rapamycin complex $1, \mathrm{p} 53$, fatty acid synthase and other molecules that regulate cell growth and metabolism. A previous study found that Met-induced 786-O cell cycle arrest involved AMPK activation (22). This is consistent with the findings of the present study that AMPK activation is involved in cell cycle arrest induced by Met in A498 cells.

Cell cycle regulation is mainly controlled by cyclin-dependent kinases $(23,24)$. Previous studies have demonstrated the importance of cell cycle deregulation in different types of human cancer (25). High protein expression levels of cyclin D1 are often found in RCCs. Inhibition of cyclin D1 may be a potential molecular target for the control of RCC $(26,27)$. A previous study demonstrated that Met arrested 786-O cells in the G0/G1 phase and found that this was correlated with decreased cyclin D1 expression (22). Similarly, the present study demonstrated that Met regulated the cell cycle of A498 cells by increasing the percentage of cells in the G0/G1 phase with a concurrent decrease in the percentage of cells in the $\mathrm{S}$ phase, which correlated with a decrease in the expression of cyclin D1. These results demonstrate that Met may be a potential therapeutic agent for the treatment of RCC.

Apoptosis suppresses proliferation (28) and Bcl-2 family members are known to be important in response to various types of apoptosis, including myocardial apoptosis, endothelial cell apoptosis and cancer cell apoptosis (29-32). Bcl-2 and Bax are recognized as classic factors in the regulation of apoptosis (33-36). Therefore, in the present study, flow cytometric analysis was used to detect the pro-apoptotic effect induced by Met, and the molecular mechanisms by which Met induced apoptosis were examined. Using flow cytometry, it was demonstrated that Met induced apoptosis, which illustrates the inhibitory effect of Met on cell growth and survival. The alterations in the expression of $\mathrm{Bcl}-2$ and Bax in A498 cells treated with Met were then investigated and it was found that Bax expression increased and $\mathrm{Bcl}-2$ expression decreased. These results indicate that Met-induced upregulation of Bax expression and downregulation of Bcl-2 expression may co-operate to induce apoptosis of A498 cells.

MMPs have been demonstrated to be crucial proteinases in the process of invasion and metastasis of RCC (37-39), including proteolytic degradation of the extracellular matrix, alterations in cell-cell extracellular matrix interactions and migration (40). Increased expression of MMP-2 proteins in patients with RCC correlates with a poor prognosis (38). The inhibitory effect of Met on the migration and invasion of A498 cells was investigated using the scratch and transwell assays. Furthermore, the protein expression levels of MMP-2 in A498 cells following treatment with Met were detected and it was found that decreased expression of MMP-2 following Met treatment was associated with the inhibition of migration and invasion in A498 cells. 
In conclusion, the present study demonstrated that Met inhibits A498 cell proliferation, induces apoptosis by regulating the expression of $\mathrm{Bcl}-2$ family members and reduces the expression of cyclin D1, which contributes to G1 cell cycle arrest of A498 cells. Furthermore, it was demonstrated that Met inhibits A498 cell migration and invasion by decreasing MMP-2 expression. In combination, these results provide in vitro evidence to support the use of Met as a novel and efficient candidate for the treatment of RCC.

\section{Acknowledgements}

This study was supported by the National Natural Science Foundation of China (grant no. 81172435).

\section{References}

1. Li L, Gao Y, Zhang L, Zeng J, He D and Sun Y: Silibinin inhibits cell growth and induces apoptosis by caspase activation, down-regulating survivin and blocking EGFR-ERK activation in renal cell carcinoma. Cancer Lett 272: 61-69, 2008.

2. Siegel R, Naishadham D and Jemal A: Cancer statistics, 2013. CA Cancer J Clin 63: 11-30, 2013.

3. Bukowski RM: Natural history and therapy of metastatic renal cell carcinoma: the role of interleukin-2. Cancer 80: 1198-1220, 1997.

4. Rabinovitch RA, Zelefsky MJ, Gaynor JJ and Fuks Z: Patterns of failure following surgical resection of renal cell carcinoma: implications for adjuvant local and systemic therapy. J Clin Oncol 12: 206-212, 1994.

5. Baaten G, Voogd AC and Wagstaff J: A systematic review of the relation between interleukin-2 schedule and outcome in patients with metastatic renal cell cancer. Eur J Cancer 40: 1127-1144, 2004.

6. Zhan HL, Gao X, Zhou XF, Pu XY and Wang DJ: Presence of tumour-infiltrating FOXP $3^{+}$lymphocytes correlates with immature tumour angiogenesis in renal cell carcinomas. Asian Pac J Cancer Prev 13: 867-872, 2012.

7. Abe $\mathrm{H}$ and Kamai $\mathrm{T}$ : Recent advances in the treatment of metastatic renal cell carcinoma. Int J Urol 20: 944-955, 2013.

8. Witters LA: The blooming of the French lilac. J Clin Invest 108: 1105-1107, 2001.

9. Ruiter R, Visser LE, van Herk-Sukel MP, et al: Lower risk of cancer in patients on metformin in comparison with those on sulfonylurea derivatives: results from a large population-based follow-up study. Diabetes Care 35: 119-124, 2012.

10. Lee MS, Hsu CC, Wahlqvist ML, Tsai HN, Chang YH and Huang YC: Type 2 diabetes increases and metformin reduces total, colorectal, liver and pancreatic cancer incidences in Taiwanese: a representative population prospective cohort study of 800,000 individuals. BMC Cancer 11: 20, 2011.

11. Wu N, Gu C, Gu H, Hu H, Han Y and Li Q: Metformin induces apoptosis of lung cancer cells through activating JNK/p38 MAPK pathway and GADD153. Neoplasma 58: 482-490, 2011.

12. Storozhuk Y, Hopmans SN, Sanli T, et al: Metformin inhibits growth and enhances radiation response of non-small cell lung cancer (NSCLC) through ATM and AMPK. Br J Cancer 108 2021-2032, 2013.

13. Fang Z, Tang Y, Fang J, et al: Simvastatin inhibits renal cancer cell growth and metastasis via AKT/mTOR, ERK and JAK2/STAT3 pathway. PloS One 8: e62823, 2013.

14. Fang Z, Tang Y, Jiao W, et al: Nitidine chloride inhibits renal cancer cell metastasis via suppressing AKT signaling pathway. Food Chem Toxicol 60: 246-251, 2013.

15. Pollak M: Metformin and other biguanides in oncology: advancing the research agenda. Cancer Prev Res (Phila) 3: $1060-1065,2010$.

16. Dowling RJ,Zakikhani M, Fantus IG, Pollak M and Sonenberg N: Metformin inhibits mammalian target of rapamycin-dependent translation initiation in breast cancer cells. Cancer Res 67: 10804-10812, 2007.

17. Ben Sahra I, Le Marchand-Brustel Y, Tanti JF and Bost F: Metformin in cancer therapy: a new perspective for an old antidiabetic drug? Mol Cancer Ther 9: 1092-1099, 2010.
18. Xiong Y, Lu QJ, Zhao J and Wu GY: Metformin inhibits growth of hepatocellular carcinoma cells by inducing apoptosis via mitochondrion-mediated pathway. Asian Pac J Cancer Prev 13: 3275-3279, 2012

19. Goodwin PJ, Ligibel JA and Stambolic V: Metformin in breast cancer: time for action. J Clin Oncol 27: 3271-3273, 2009.

20. Okoshi R, Ozaki T, Yamamoto $\mathrm{H}$, et al: Activation of AMP-activated protein kinase induces p53-dependent apoptotic cell death in response to energetic stress. J Biol Chem 283: 3979-3987, 2008.

21. Chen MB, Wu XY, Gu JH, Guo QT, Shen WX and Lu PH: Activation of AMP-activated protein kinase contributes to doxorubicin-induced cell death and apoptosis in cultured myocardial H9c2 cells. Cell Biochem Biophys 60: 311-322, 2011.

22. Liu J, Li M, Song B, et al: Metformin inhibits renal cell carcinoma in vitro and in vivo xenograft. Urol Oncol 31: 264-270, 2013.

23. Senderowicz AM: Targeting cell cycle and apoptosis for the treatment of human malignancies. Curr Opin Cell Biol 16: 670-678, 2004.

24. Schwartz GK and Shah MA: Targeting the cell cycle: a new approach to cancer therapy. J Clin Oncol 23: 9408-9421, 2005.

25. Alao JP: The regulation of cyclin D1 degradation: roles in cancer development and the potential for therapeutic invention. Mol Cancer 6: 24, 2007.

26. Song E, Ma X, Li H, et al: Attenuation of krüppel-like factor 4 facilitates carcinogenesis by inducing $\mathrm{g} 1 / \mathrm{s}$ phase arrest in clear cell renal cell carcinoma. PloS One 8: e67758, 2013.

27. Laviolette LA, Wilson J, Koller J, et al: Human folliculin delays cell cycle progression through late $\mathrm{S}$ and $\mathrm{G} 2 / \mathrm{M}$-phases: effect of phosphorylation and tumor associated mutations. PloS One 8: e66775, 2013.

28. Circu ML and Aw TY: Glutathione and modulation of cell apoptosis. Biochim Biophys Acta 1823: 1767-1777, 2012.

29. Andersen JL and Kornbluth S: The tangled circuitry of metabolism and apoptosis. Mol Cell 49: 399-410, 2013.

30. Petsophonsakul P, Pompimon W and Banjerdpongchai R: Apoptosis induction in human leukemic promyelocytic HL-60 and monocytic U937 cell lines by goniothalamin. Asian Pac J Cancer Prev 14: 2885-2889, 2013.

31. Smith MA and Schnellmann RG: Calpains, mitochondria, and apoptosis. Cardiovasc Res 96: 32-37, 2012.

32. Czabotar PE, Lessene G, Strasser A and Adams JM: Control of apoptosis by the BCL-2 protein family: implications for physiology and therapy. Nat Rev Mol Cell Biol 15: 49-63, 2014.

33. Hasan TN, B LG, Shafi G, Al-Hazzani AA and Alshatwi AA: Anti-proliferative effects of organic extracts from root bark of Juglans Regia L. (RBJR) on MDA-MB-231 human breast cancer cells: role of Bcl-2/Bax, caspases and Tp53. Asian Pac J Cancer Prev 12: 525-530, 2011.

34. Zhang N, Kong X, Yan S, Yuan C and Yang Q: Huaier aqueous extract inhibits proliferation of breast cancer cells by inducing apoptosis. Cancer Sci 101: 2375-2383, 2010.

35. Zhang N, Wang X, Huo Q, et al: The oncogene metadherin modulates the apoptotic pathway based on the tumor necrosis factor superfamily member TRAIL (tumor necrosis factor-related apoptosis-inducing ligand) in breast cancer. J Biol Chem 288: 9396-9407, 2013.

36. Youle RJ and Strasser A: The BCL-2 protein family: opposing activities that mediate cell death. Nature Rev Mol Cell Biol 9: 47-59, 2008.

37. Himelstein BP, Lee EJ, Sato H, Seiki M and Muschel RJ: Tumor cell contact mediated transcriptional activation of the fibroblast matrix metalloproteinase-9 gene: involvement of multiple transcription factors including Ets and an alternating purine-pyrimidine repeat. Clin Exp Metastasis 16: 169-177, 1998.

38. Kallakury BV, Karikehalli S, Haholu A, Sheehan CE, Azumi N and Ross JS: Increased expression of matrix metalloproteinases 2 and 9 and tissue inhibitors of metalloproteinases 1 and 2 correlate with poor prognostic variables in renal cell carcinoma. Clin Cancer Res 7: 3113-3119, 2001.

39. Hu Y and Ivashkiv LB: Costimulation of chemokine receptor signaling by matrix metalloproteinase- 9 mediates enhanced migration of IFN-alpha dendritic cells. J Immunol 176: 6022-6033, 2006.

40. Gialeli C, Theocharis AD and Karamanos NK: Roles of matrix metalloproteinases in cancer progression and their pharmacological targeting. FEBS J 278: 16-27, 2011. 